\title{
Lenguaje, arte y filosofía en Kant, Pedro A. Viñuela Villa
}

Carmen Sánchez Polo

\section{Pedro A. Viñuela Villa}

\section{LENGUAJE, ARTE}

Y FILOSOFIA EN KANT

Trahajo académica

UNED

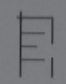

kesirun Edokionse

Pedro A. Viñuela Villa. Lenguaje, arte y filosofía en Kant. Madrid: Ápeiron Ediciones, 2018.
Ápeiron Ediciones ha publicado Lenguaje, arte y filosofia en Kant, un estudio académico de Pedro A. Viñuela Villa, actual profesor asociado en la Universidad Internacional de La Rioja e investigador especializado fundamentalmente en filosofía moderna y filosofía e historia de la matemática. El libro se presenta como una investigación en torno a la cuestión del lenguaje en la filosofía kantiana, motivada por las acusaciones que tradicionalmente se le han hecho, y según las cuales existiría en la misma un "olvido del lenguaje”. Así pues, Viñuela trata de poner de relieve en este estudio que tales acusaciones se deben a "otro olvido": el de los escritos kantianos sobre antropología y gran parte de 
la Crítica del juicio (1790), donde el prusiano realiza múltiples consideraciones sobre el lenguaje.

Así, la tesis que se defiende, y que encontramos ya adelantada en la "Introducción", apunta a que, si bien en Kant no hay estrictamente una filosofía del lenguaje, sí hay al menos una reflexión sobre el mismo, aunque no esté articulada de forma sistemática. Para defender esta proposición, el autor lleva a cabo una reinterpretación de la filosofía de Kant que centra el foco de atención, sobre todo, en las obras antes mencionadas, y a partir de la adopción del enfoque del giro lingüístico de la filosofía en el siglo xx, según el cual toda teoría del conocimiento está atravesada por una determinada concepción del lenguaje. En el caso de la filosofía kantiana, dicha concepción no tiene por qué ser entendida en términos "propiamente lingüísticos", sino por medio de nociones como comunicabilidad (Mittheilbarkeit), sociabilidad (Geselligkeit), genio (genius) o gusto (Beurtheilungsvermögen).

Desde el capítulo segundo hasta el ocho, se recoge una serie de consideraciones que Kant hace sobre el puesto/ lugar del lenguaje en el pensamiento, así como también en el conocimiento -donde tendrían un lugar tanto la intuición como la imaginación-. Aunque tales consideraciones se hallan, en su mayoría, recogidas en la Crítica del juicio y las lecciones de antropología, el autor no pierde de vista lo que Kant dice en sus obras principales, como la Crítica de la razón pura. De este modo, a medida que el autor va recogiendo dichas consideraciones, va situándolas en el sistema kantiano en torno a la cuestión que ocupa a esta obra.

Viñuela sostiene que, en Kant, pensamiento y lenguaje están unidos porque al primero siempre le corresponde, por esencia, una expresión lingüística mediante la cual manifestarse $y$ hacerse perceptible $-o$ comunicable- a los demás. A juicio del autor, es en el análisis de los actos judicativos donde esto se ve de modo más claro, aunque también resultan destacables las aportaciones sobre el tratamiento que Kant hace del signo (Zeichen), como el elemento que pone en relación las intuiciones sensibles con los conceptos lingüísticos.

Ahora bien, Viñuela sostiene que para profundizar en la cuestión del lenguaje es pertinente vincular la 
perspectiva antropológica con la teoría kantiana del conocimiento y del signo. Desde ésta, el lenguaje es concebido como el medio esencial sin el cual el ser humano no podría transmitir sus pensamientos a los demás. Dado que la comunicabilidad es lo que para Kant define la humanidad o la esencia del ser humano (Menschheit), el lenguaje ha de ser la naturaleza que defina tanto la comunicación como el pensamiento. De ahí que Vinuela proponga, como tesis acerca de lo que en Kant es el lenguaje, que el pensamiento es un discurso interior, haciéndolo coincidir en esto con autores anteriores como Platón, Locke o Leibniz, pero también con autores coetáneos como Herder.

La segunda parte de la obra queda dedicada a recoger lo que Kant señala sobre el lenguaje a propósito de la estética y del arte en la Critica del juicio. En esta parte resulta destacable la llamada de atención del autor sobre el papel que Kant otorga a nociones como el simbolo (Symbola) que, siendo un elemento muy recurrente en el lenguaje cotidiano, se trata de un tipo de intuición que transporta al intelecto humano hacia un ámbito de significación que traspasa los límites de lo estrictamente conceptual. Otras nociones que se destacan, ya desde el ámbito del arte y la estética, son las ideas estéticas y el genio. A partir de ellas, Viñuela señala que existe un ámbito en la filosofía de Kant donde el lenguaje toma otros tipos de expresión más allá de la estrictamente lingüística, que se materializan en el "arte bello”. Así, mediante la interpretación de estas distintas nociones, se acerca al lector no sólo a una concepción del lenguaje kantiano, sino también hacia un tipo de filosofía, propuesta por el mismo Kant, que no es ya la filosofía especulativa, sino que se trata de una en un sentido más pragmático, más alejada de las cuestiones puramente especulativas del conocimiento y más cercana las cuestiones que tienen que ver de forma directa con los fines de la humanidad.

A este respecto, la conclusión resulta aclaradora y hace muy asequible entender el desarrollo del planteamiento de Pedro A. Viñuela. Así, es posible observar las aportaciones concretas que el autor realiza para dar pie a pensar una posible concepción del lenguaje en la filosofía kantiana: primero, 
que no es cierto que en Kant exista en verdad un olvido del lenguaje, y segundo, que la vinculación del pensamiento kantiano con el de la tradición precedente y la relevancia de los textos sobre antropología y estética no sólo sirven para reconstruir una reflexión sobre el lenguaje, sino también, y de manera adicional, para dar cuenta de la existencia de una segunda acepción de filosofía en la teoría del prusiano. Por todo ello, este estudio resulta imprescindible para una investigación acerca de la concepción kantiana del lenguaje, no sólo en el ámbito del conocimiento teórico, sino también en el ámbito práctico, pragmático o, incluso, estético de la filosofía. 